\title{
Obesity and Knee Arthroscopy - a Review
}

\author{
Mariana Tilinca', Tudor Sorin Pop², Tiberiu Bățagă³, Ancuța Zazgyva', Marius Niculescu \\ 1 Department of Cell and Molecular Biology, Faculty of Medicine, University of Medicine and Pharmacy, Tîrgu Mureș, Romania \\ 2 Department of Orthopedics and Traumatology I, Faculty of Medicine, University of Medicine and Pharmacy, Tîrgu Mureș, Romania \\ 3 Department of Orthopedics and Traumatology II, Faculty of Medicine, University of Medicine and Pharmacy, Tîrgu Mureș, Romania \\ 4 Department of Orthopedics and Traumatology, Faculty of Medicine, Titu Maiorescu University, Bucharest, Romania
}

\section{CORRESPONDENCE}

\section{Ancuța Zazgyva}

Str. Gheorghe Marinescu nr. 38

540139 Tîrgu Mureș, Romania

Tel: +40 745612397

E-mail: zazgyvaa@yahoo.com
Mariana Tilinca • Str. Gheorghe Marinescu nr. 38, 540139 Tîrgu Mureș, Romania, Tel: +40 265215 551, E-mail: mariana.tilinca@umftgm.ro

Tudor Sorin Pop • Str. Gheorghe Marinescu nr. 38, 540139 Tîrgu Mures, Romania, Tel: +40 265215 551, E-mail: tudorsorin.pop@umftgm.ro

Tiberiu Bățagă • Str. Gheorghe Marinescu nr. 38 540139 Tîrgu Mureș, Romania, Tel: +40 265215 551, E-mail: tbataga@gmail.com

Marius Niculescu • Str. Dâmbovnicului nr. 22, 04044 Bucuresti, Romania. Tel: +40 213161 646, E-mail: mariusniculescu.ortoped@gmail.com

\section{ABSTRACT}

Obesity is currently a global epidemic, often referred to as "globesity", impacting the life of millions worldwide. A risk factor for many diseases, obesity can also be linked to developing intra-articular lesions of the knee, affecting the menisci, ligaments and cartilage. Furthermore, obesity has been shown to influence the outcome of surgical interventions, including those of the musculoskeletal system. Although many studies addressed the relationship of obesity and joint replacement, articles relating to arthroscopy and obesity, and knee arthroscopy in particular, are a bit scarcer. The majority of data suggest that an increase in BMI leads to a similar increase in the rates of intra- and postoperative complications, and most authors agree that a higher body mass index can influence both the procedure itself and its outcomes, including the subjective results reported by the patients. Still, some studies show different results, especially in patients that are overweight or with low-grade obesity, where the outcomes are comparable to those of the non-obese population. Thus, it can be concluded that obesity is an important patient characteristic that needs to be taken into consideration when planning, performing, and assessing the results of knee arthroscopy.

Keywords: obesity, arthroscopy, articular lesions

\section{OBESITY - A GLOBAL ISSUE}

Obesity has grown into a worldwide epidemic, with over one billion people affected and with a multitude of associated health problems and risks. A recent pooled analysis of 1.698 population-based studies, including over 19 million participants, has concluded that the prevalence of obesity has been increasing all around the world, and by 2025 , an estimated $18 \%$ of men and over $20 \%$ of women will be obese, while severe obesity will have a prevalence of over $6 \%$ in men and $9 \%$ in women. ${ }^{1}$ In the USA, obesity rates in both adults and children are alarmingly high $-37.7 \%$ and $17 \%$, respectively. ${ }^{2-5}$ Similarly high rates of obesity are also present in many European countries, especially the UK, Malta, Latvia, Hungary and Estonia. The 2008 International Association for the Study of Obesity (IASO) data for EU27 provided high obesity rate estimates - over $53 \%$ of the EU population being overweight or obese. ${ }^{6}$ This means $>143$ million overweight adults and 68.5 million obese adults. More males are overweight com- 
pared to females, but more females are obese compared to males. Interestingly, overweight and obesity rates in Romania are lower compared to other European countries; obesity rates amongst Romanian males was the second lowest in Europe (7.6\%, second only to Sweden's 7.0\%), with similarly low rates in women. Still, data released in 2013 by the World Health Organization (WHO) predicted an increase in the incidence of obesity for Romania, affecting $12 \%$ of men and $9 \%$ of women by 2020 , and $15 \%$ of men and $10 \%$ of women by $2030 .^{7}$

Although it has been shown that there is a genetic predisposition for obesity, an obesogenic environment can also be blamed. ${ }^{8}$ The latter is based on the abundance of high-caloric foods with a low nutritional value, coupled with reduced energy expenditures, all related to the westernized lifestyle that has been gaining more popularity worldwide since the 1980's. The root causes of "globesity" seem to be governmental policies and the food industry. ${ }^{9,10}$

\section{OBESITY AND PATHOLOGY}

Obesity is a risk factor for a whole array of conditions, from infectious diseases to cancer. ${ }^{11-17}$ The most wellknown association is that of obesity with cardiovascular diseases (including atrial fibrillation, hypertension and heart failure) and type 2 diabetes mellitus. ${ }^{18-26}$ There is also a well-documented effect of obesity on the large joints of the lower limb, with changes in joint biomechanics and biology, often leading to osteoarthritis (OA).27-36 Furthermore, obesity has been shown to have a negative effect on postoperative outcomes of many surgical interventions, including those of orthopedics and traumatology. ${ }^{37-43}$

Intra-articular lesions and changes of the knee, including those of the menisci, cruciate ligaments and synovial membrane, have been linked to obesity in many studies. ${ }^{44-50}$ More importantly, obesity seems to be related to lesions of the articular cartilage of the knee, even in the absence of $\mathrm{OA}$, in adults and children alike..$^{51-57}$

\section{KNEE BIOMECHANICS IN OBESITY AND THE MOLECULAR LINK}

With the increase in body weight and mass, obesity alters the way the body creates and reacts to forces. Depending on body mass distribution, obesity can modify the body's center of mass, creating imbalances that can influence gait and stability. ${ }^{58}$ If these changes are present from childhood, they can be predisposing factors for knee angular deformities, thus possibly leading to OA in adults. ${ }^{59,60} \mathrm{Ex}$ - cess adiposity also reduces joint range of motion, consequently changing functional movement. ${ }^{61,62}$ The increased ground reaction forces, and compressive and shear forces produced by obesity in the knee joint might be causative factors for developing cartilage lesions that can evolve towards OA. ${ }^{32,63}$

As obesity is also associated with the presence of OA in non-weight bearing joints, it seems that the connection between the two must also be related to other factors besides the biomechanics of overload. Many researchers sought the answer to the question: what links obesity to cartilage lesions at a molecular level? Unfortunately, the precise underlying cellular and molecular mechanisms are still not clear, but there has been a lot of progress in this direction. Basically, OA is now considered an inflammatory disease rather than one caused by "wear and tear". ${ }^{64}$ It seems that the involved inflammation can be triggered by the innate immune system, local production of inflammatory mediators, aging, or even estrogen regulation. ${ }^{64}$

In their 2011 review article, Bonet et al. offer a thorough analysis of the molecular links between obesity and OA, identifying adipose tissue-derived inflammatory mediators, oxidative stress and hyperlipidemia as risk factors for joint degeneration. ${ }^{65}$ They also outlined the regulatory factors involved in the maintenance and function of both the adipose tissue and articular joint tissues, such as the adipocytokines resistin, leptin, interleukin (IL) $1 \beta$, IL-6, and tumor necrosis factor alpha (TNF- $\alpha$ ), which are involved in the pathophysiology of obesity and OA. ${ }^{65,66}$

From the mentioned cytokines produced by the adipose tissue, leptin seems to be an excellent candidate for a mediator that links obesity to OA. Not only do obese patients present increased levels of leptin in their synovial fluid, but also an enhanced sensitivity of the cartilage for leptin. Cartilage expresses leptin receptors, through which this metabolic regulator hormone can induce the production of nitric oxide ( $\mathrm{NO}$ ), pro-inflammatory cytokines and matrix metalloproteinases (MPPs), leading to cartilage destruction. ${ }^{66-69}$

Interestingly, biomechanical factors can also influence the development of OA through the activation of cellular inflammation and the promotion of oxidative stress. ${ }^{69}$ Hence abnormal mechanical joint stress such as stretch, compression of shear forces, are detected by the mechanoreceptors on cells from the joint surface. These in turn convert these mechanical signals into intracellular ones, resulting in the overexpression of prostaglandins, cytokines and chemokines, mainly through the nuclear factor-kB (NF-kB) and mitogen-activated protein kinase (MAPK) pathways. ${ }^{64}$ 


\section{OBESITY AND KNEE ARTHROSCOPY}

Although recently there has been some debate about the usefulness of knee arthroscopy as a therapeutic technique, the procedure is still very effective if the indications are well chosen..$^{70-74}$ Additionally, the advantages related to the minimally invasive nature of the technique usually recommend it as a better option compared to procedures involving arthrotomy.

Like any other surgical intervention, knee arthroscopy does have certain potential complications. These include deep venous thrombosis, pulmonary embolus, infections, and even nerve and vascular injury, as well as iatrogenic chondral injury. Some of the used materials and devices (screws, fixation devices, bioabsorbable materials, etc) also have associated complications. By analyzing self-reported complication rates for 92,565 knee arthroscopic procedures, Salzler et al. found an overall complication rate of $4.7 \%$, of which surgical complications accounted for $3.68 \% .{ }^{75}$ Unfortunately, they only assessed patient age and gender, and body mass index (BMI) was not taken into account. However, in a similar study, Hagino et al. reported a much lower complication rate of $0.27 \%$ ( 7 out of the 2,623 cases studied). ${ }^{76}$

The role of obesity has been long debated in knee surgery - both arthroscopy and arthroplasty. When investigating the relationship between obesity and knee arthroscopy, studies have looked at how different intra-articular pathologies relate to obesity, and whether the outcomes of the procedures are influenced in any way by the patient's weight status. ${ }^{77}$ In their prospective study of 541 patients undergoing ACL reconstruction, Kluczynski et al. found that obesity was associated with more chondral injuries. ${ }^{78}$ Similarly, Ciccotti et al. reported a correlation of articular cartilage lesions with elevated BMI in their cohort of 1,010 patients undergoing knee arthroscopy for meniscal pathologies. ${ }^{79}$ Other authors have also suggested that a high BMI might be a risk factor for meniscal, ligamentous and cartilage injuries of the knee..$^{80-83}$

\section{MORBID OBESITY AND KNEE ARTHROSCOPY}

Morbid obesity is defined as BMI over 40 or 50, and it implies very complex health issues. Unfortunately, in many countries there is a fast growth of morbid obesity rates. ${ }^{84}$

Many studies looked at how morbid obesity is connected to knee arthroplasty outcomes, but only a few studies have analyzed knee arthroscopy, and they are mostly concerned with the technical difficulties encountered in this category of patients. Berg performed a retrospective assessment of 10 patients with morbid obesity, compared to 10 normal weight patients matched for age, sex, and surgical procedure, in order to identify surgical morbidity and specific technical difficulties. ${ }^{85} \mathrm{He}$ found that operative and anesthetic times were greater, possibly because of the difficulties in identifying bony landmarks and the need for using more arthroscopy portals. It might also be hard to find appropriate tourniquets and leg holders for these patients. The author also noted that postoperative assessment was hampered by the size of the knees, and patient recovery and return to normal activities took longer when compared to the normal weight controls.

In their technical note published in 2002, Martinez et al. present their recommendations for performing knee arthroscopy in the morbidly obese, with advice regarding patient positioning and portal placement for appropriate visualization of intra-articular structures. ${ }^{86}$

\section{INTRA- AND POSTOPERATIVE COMPLICATIONS AND OUTCOMES}

The questions if obesity negatively influences the outcomes of knee arthroscopic procedures, and whether it represents a contraindication in these cases are even more important in view of the growing trend towards overweight and obesity worldwide.

When evaluating studies aimed to identify the influence of overweight and obesity on surgical outcomes, it is important to keep in mind that in retrospective studies based on patient records, obesity might be under-reported. Goode et al. found that International Classification of Diseases (ICD) diagnoses codes were more likely to be used in extremely obese patients, while for those with BMI ranging from $25-40 \mathrm{~kg} / \mathrm{m}^{2}$ the appropriate diagnostic codes were used in only $10 \%$ of cases. ${ }^{87}$

Obesity seems to be associated with a significant increase in postoperative complication rates following knee arthroscopy, but BMI is not sufficient for accurately predicting these complications, and other health factors related to obesity also have to be considered. ${ }^{88,89}$

For arthroscopic meniscus surgery, some studies suggest inferior short-term outcomes of partial meniscectomy in obese compared to non-obese patients, while for meniscus repair, it seems that a $\mathrm{BMI} \geq 25$ does not increase the risk of failure. ${ }^{90,91}$ In terms of anterior cruciate ligament (ACL) reconstruction, although obese patients can certainly benefit from the procedure, obesity seems to be a strong predictor of knee OA after ACL reconstruction. ${ }^{92,93}$

Some authors investigated patient-reported outcomes of knee arthroscopy in the overweight and obese, and 
reported a negative influence of higher BMI. The questionnaire-based study of Harrison et al. revealed that both quality of life and satisfaction with surgery are lower in overweight compared to normal-weight women. ${ }^{94} \mathrm{~Pa}$ tient-reported outcomes after ACL reconstruction are also negatively influenced by obesity, especially the perception on joint function. ${ }^{95-97}$ Interestingly, others have found that subjective results of obese patients are comparable to those of the non-obese. ${ }^{98}$

\section{CONCLUSIONS}

Obesity is a risk factor for developing intra-articular lesions of the knee, and has been shown to influence the outcome of surgical interventions, including those of the musculoskeletal system. Many studies addressed the relationship of obesity and joint replacement, but those relating to arthroscopy and obesity, and knee arthroscopy in particular, are a bit scarcer. Most authors agree that a higher body mass index can influence both the procedure itself and its outcomes, including the subjective results reported by the patient, but some have suggested that the outcomes of overweight/low-grade obesity patients are comparable to those of the non-obese population. Thus, it can be concluded that obesity is an important patient characteristic that needs to be taken into consideration when planning, performing, and assessing the results of knee arthroscopy.

\section{CONFLICT OF INTEREST}

Nothing to declare.

\section{REFERENCES}

1. Collaboration NCDRF. Trends in adult body-mass index in 200 countries from 1975 to 2014: a pooled analysis of 1698 population-based measurement studies with 19.2 million participants. Lancet. 2016;387:13771396.

2. Seidell JC, Halberstadt J. Obesity: The obesity epidemic in the USA - no end in sight? Nat Rev Endocrinol. 2016;12:499-500.

3. Flegal KM, Kruszon-Moran D, Carroll MD, Fryar CD, Ogden CL. Trends in Obesity Among Adults in the United States, 2005 to 2014. JAMA. 2016;315:2284-2291.

4. Ogden CL, Carroll MD, Lawman HG, et al. Trends in Obesity Prevalence Among Children and Adolescents in the United States, 1988-1994 Through 2013-2014. JAMA. 2016;315:2292-2299.

5. Cheung PC, Cunningham SA, Naryan KM, Kramer MR. Childhood Obesity Incidence in the United States: A Systematic Review. Child Obes. 2016;12:1-11.

6. International Association for the Study of Obesity. Overweight \& Obesity in the EU27 July 2008. Available online at: http://www.worldobesity.org/ site_media/uploads/v2PDFforwebsiteEU27.pdf.

7. World Health Organization. Nutrition, Physical Activity and Obesity Romania 2013. Available online at: http://www.euro.who.int/_data/assets/ pdf_file/0014/243320/Romania-WHO-Country-Profile.pdf?ua=1.

8. Pinto Pereira SM, van Veldhoven K, Li L, Power C. Combined early and adult life risk factor associations for mid-life obesity in a prospective birth cohort: assessing potential public health impact. BMJ Open 2016;6:e011044.

9. Castelnuovo G, Pietrabissa G, Manzoni GN, et al. Chronic care management of globesity: promoting healthier lifestyles in traditional and mHealth based settings. Front Psychol. 2015;6:1557.

10. Lifshitz F, Lifshitz JZ. Globesity: the root causes of the obesity epidemic in the USA and now worldwide. Pediatr Endocrinol Rev. 2014;12:17-34.

11. Grier WR, Kratimenos P, Singh S, Guaghan JP, Koutroulis I. Obesity as a Risk Factor for Urinary Tract Infection in Children. Clin Pediatr (Phila). 2016;55:952-956.

12. Murphy R, Fragaszy EB, Hayward AC, Warren-Gash C. Investigating obesity as a risk factor for influenza-like illness during the 2009 H1N1 influenza pandemic using the Health Survey for England. Influenza Other Respir Viruses. 2016. [Epub ahead of print]

13. Kessous R, Davidson E, Meirovitz M, Sergienko R, Sheiner E. Prepregnancy obesity: a risk factor for future development of ovarian and breast cancer Eur J Cancer Prev. 2016. [Epub ahead of print]

14. Hwang Y, Lee KE, Park YJ, et al. Annual Average Changes in Adult Obesity as a Risk Factor for Papillary Thyroid Cancer: A Large-Scale Case-Control Study. Medicine (Baltimore). 2016;95:e2893.

15. Thapa JR, Lyford C, McCool B, Pence B, McCool A, Belasco E. Improving Cancer Risk Awareness Including Obesity as a Risk Factor for Cancer in a Small U.S. Community. J Cancer Educ. 2016.

16. Li L, Liu DW, Yan HY, Wang ZY, Zhao SH, Wang B. Obesity is an independent risk factor for non-alcoholic fatty liver disease: evidence from a metaanalysis of 21 cohort studies. Obes Rev. 2016;17:510-519.

17. Qian J, Ren X. Obesity is a risk factor for asthma in women but not in men among elder people in China. Eur J Intern Med. 2016. [Epub ahead of print]

18. Bhupathiraju SN, Hu FB. Epidemiology of Obesity and Diabetes and Their Cardiovascular Complications. Circ Res. 2016;118:1723-1735.

19. Miner SE, Nield LE. Obesity Cardiovascular Disease and the Failure of Public Health Education. J Am Coll Cardiol. 2016;67:2315-2316.

20. Ergun G, Basaran O, Doğan V, Doğan MM, Biteker M. Obesity and atrial fibrillation. Int J Cardiol. 2016;223:159-60.

21. Fuster JJ, Ouchi N, Gokce N, Walsh K. Obesity-Induced Changes in Adipose Tissue Microenvironment and Their Impact on Cardiovascular Disease. Circ Res. 2016;118(11):1786-807.

22. Rippe JM, Angelopoulos TJ. Sugars, obesity, and cardiovascular disease: results from recent randomized control trials. Eur J Nutr. 2016. [Epub ahead of print]

23. Ortega FB, Lavie CJ, Blair SN. Obesity and Cardiovascular Disease. Circ Res. 2016;118:1752-1770.

24. Mandviwala T, Khalid U, Deswal A. Obesity and Cardiovascular Disease: a Risk Factor or a Risk Marker? Curr Atheroscler Rep. 2016;18:21.

25. Chang Y, Jung HS, Yun KE, et al. Metabolically healthy obesity is associated with an increased risk of diabetes independently of nonalcoholic fatty liver disease. Obesity (Silver Spring). 2016;24:1996-2003.

26. Leong A, Porneala B, Dupuis J, Florez JC, Meigs JB. Type 2 Diabetes Genetic Predisposition, Obesity, and All-Cause Mortality Risk in the U.S.: A Multiethnic Analysis. Diabetes Care. 2016;39:539-546.

27. Santangelo KS, Radakovich LB, Fouts J, Foster MT. Pathophysiology of obesity on knee joint homeostasis: contributions of the infrapatellar fat pad. Horm Mol Biol Clin Investig. 2016;26:97-108.

28. Reyes C, Leyland KM, Peat G, Cooper C, Arden NK, Prieto-Alhambra D. Association Between Overweight and Obesity and Risk of Clinically Diagnosed Knee, Hip, and Hand Osteoarthritis: A Population-Based Cohort Study. Arthritis Rheumatol. 2016;68:1869-1875.

29. Deshpande BR, Katz JN, Solomon DH, et al. The number of persons with symptomatic knee osteoarthritis in the United States: Impact of race/ ethnicity, age, sex, and obesity. Arthritis Care Res (Hoboken). 2016. [Epub ahead of print]

30. Frilander H, Viikari-Juntura E, Heliövaara M, Mutanen P, Mattila VM, Solovieva S. Obesity in early adulthood predicts knee pain and walking difficulties among men: A life course study. Eur J Pain. 2016;20:1278-1287.

31. DeVita P, Rider P, Hortobágyi T. Reductions in knee joint forces with weight loss are attenuated by gait adaptations in class III obesity. Gait Posture. 2016;45:25-30.

32. Harding GT, Dunbar MJ, Hubley-Kozey CL, Stanish WD, Astephen Wilson $\mathrm{JL}$. Obesity is associated with higher absolute tibiofemoral contact and muscle forces during gait with and without knee osteoarthritis. Clin Biomech (Bristol, Avon). 2016:31:79-86.

33. Leyland KM, Judge A, Javaid MK, et al. Obesity and the Relative Risk of Knee Replacement Surgery in Patients With Knee Osteoarthritis: A Prospective Cohort Study. Arthritis Rheumatol. 2016;68:817-825. 
34. Travascio F, Eltoukhy M, Cami S, Asfour S. Altered mechano-chemical environment in hip articular cartilage: effect of obesity. Biomech Model Mechanobiol. 2014;13:945-959

35. Teichtahl AJ, Wang Y, Smith S, et al. Early cartilage abnormalities at the hip are associated with obesity and body composition measures - a 3.0T MRI community-based study. Arthritis Res Ther. 2015;17:107.

36. Anandacoomarasamy A, Caterson I, Sambrook P, Fransen M, March L. The impact of obesity on the musculoskeletal system. Int J Obes (Lond). 2008;32:211-222.

37. Ma Z, Guo F, Qi J, Xiang W, Zhang J. Meta-analysis shows that obesity may be a significant risk factor for prosthetic joint infections. Int Orthop. 2016;40:659-667.

38. Werner BC, Higgins MD, Pehlivan HC, Carothers JT, Browne JA. Super Obesity Is an Independent Risk Factor for Complications After Primary Total Hip Arthroplasty. J Arthroplasty. 2016. [Epub ahead of print]

39. Fu MC, D'Ambrosia C, McLawhorn AS, Schairer WW, Padgett DE, Cross MB. Malnutrition Increases With Obesity and Is a Stronger Independent Risk Factor for Postoperative Complications: A Propensity-Adjusted Analysis of Total Hip Arthroplasty Patients. J Arthrop/asty. 2016;31(11):2415-2421.

40. Calder CL, Ortega G, Vij A, et al. Morbid obesity is an independent risk factor for postoperative renal dysfunction in young adults: a review of the American College of Surgeons National Surgical Quality Improvement Program database. Am J Surg. 2016;211:772-777.

41. Wooten C, Curtin B. Morbid Obesity and Total Joint Replacement: Is It Okay to Say No? Orthopedics. 2016;39:207-209.

42. Hussan H, Gray DM, Hinton A, Krishna SG, Conwell DL, Stanich PP.Morbid Obesity is Associated with Increased Mortality, Surgical Complications, and Incremental Health Care Utilization in the Peri-Operative Period of Colorectal Cancer Surgery. World J Surg. 2016;40:987-994.

43. Burrus MT, Werner BC, Yarboro SR. Obesity is associated with increased postoperative complications after operative management of tibial shaft fractures. Injury. 2016;47:465-470.

44. Sun AR, Friis T, Sekar S, Crawford R, Xiao Y, Prasadam I. Is Synovial Macrophage Activation the Inflammatory Link Between Obesity and Osteoarthritis? Curr Rheumatol Rep. 2016;18:57.

45. Rai MF, Patra D, Sandell LJ, Brophy RH. Relationship of gene expression in the injured human meniscus to body mass index: a biologic connection between obesity and osteoarthritis. Arthritis Rheumatol. 2014;66:21522164.

46. Rai MF, Sandell LJ, Cheverud JM, Brophy RH. Relationship of age and body mass index to the expression of obesity and osteoarthritis-related genes in human meniscus. Int J Obes (Lond). 2013;37:1238-1246.

47. Barrett GR, Thibodeaux KE, eplogle WH, Barrett A, Parks T, Baker D. Body Mass Index as an Indicator of Associated Intra-articular Injuries in Patients With Anterior Cruciate Ligament Tears. J Surg Orthop Adv. 2015;24:159163 .

48. Brambilla L, Pulici L, Carimati G. Prevalence of Associated Lesions in Anterior Cruciate Ligament Reconstruction: Correlation With Surgical Timing and With Patient Age, Sex, and Body Mass Index. Am J Sports Med. 2015;43:2966-2973.

49. Evans KN, Kilcoyne KG, Dickens JF, et al. Predisposing risk factors for non-contact ACL injuries in military subjects. Knee Surg Sports Traumatol Arthrosc. 2012;20:1554-1559.

50. Bowers AL, Spindler KP, McCarty EC, Arrigain S. Height, weight, and $\mathrm{BMI}$ predict intra-articular injuries observed during $\mathrm{ACL}$ reconstruction: evaluation of 456 cases from a prospective ACL database. Clin J Sport Med. 2005;15:9-13.

51. Lacy KW, Cracchiolo A, Yu S, Goitz H. Medial Femoral Condyle Cartilage Defect Biomechanics: Effect of Obesity, Defect Size, and Cartilage Thickness. Am J Sports Med. 2016;44:409-416

52. Teichtahl AJ, Wluka AE, Wang Y, et al. Obesity and adiposity are associated with the rate of patella cartilage volume loss over 2 years in adults without knee osteoarthritis. Ann Rheum Dis. 2009:68:909-913.

53. Blazek K, Favre J, Asay J, Erhart-Hledik J, Andriacchi T. Age and obesity alter the relationship between femoral articular cartilage thickness and ambulatory loads in individuals without osteoarthritis. J Orthop Res. 2014;32:394-402

54. Mezhov V, Ciccutini FM, Hanna FS, et al. Does obesity affect knee cartilage? A systematic review of magnetic resonance imaging data. Obes Rev. 2014;15:143-157.

55. Widhalm HK, Marlovits S, Welsch GH, et al. Obesity-related juvenile form of cartilage lesions: a new affliction in the knees of morbidly obese children and adolescents. Eur Radiol. 2012;22:672-681.

56. Jones DG. Articular cartilage degeneration: etiologic association with obesity. Ochsner J. 2009;9:137-139.
57. Haviv B, Bronak S, Thein R. Correlation between body mass index and chondral lesions in isolated medial meniscus tears. Indian J Orthop. 2015;49:176-180.

58. Del Porto HC, Pechak CM, Smith DR, Reed-Jones RJ. Biomechanica Effects of Obesity on Balance. International Journal of Exercise Science. 2012:5:301-320.

59. Gushue DL, Houck J, Lerner AL. Effects of childhood obesity on threedimensional knee joint biomechanics during walking. J Pediatr Orthop 2005;25:763-768.

60. Lerner ZF, Board WJ, Browning RC. Pediatric obesity and walking duration increase medial tibiofemoral compartment contact forces. J Orthop Res. 2016;34:97-105

61. Nantel J, Mathieu ME, Prince F. Physical activity and obesity: biomechanical and physiological key concepts. J Obes. 2011;2011:650230.

62. MacLean KFE, Callaghan JP, Maly MR. Effect of obesity on knee joint biomechanics during gait in young adults. Cogent Medicine. 2016:3:1173778.

63. Henriksen M, Jørgensen LB, Aaboe J. Obesity and Walking: Implications for Knee Osteoarthritis and Plantar Heel Pain. Curr Obes Rep. 2012;1:160-165.

64. Berenbaum F. Osteoarthritis as an inflammatory disease (osteoarthritis is not osteoarthrosis!). Osteoarthritis Cartilage. 2013;21:16-21.

65. Bonet ML, Granados N, Palou A. Molecular players at the intersection of obesity and osteoarthritis. Curr Drug Targets. 2011;12:2103-2128.

66. Sartori-Cintra AR, Aikawa P, Cintra DE. Obesity versus osteoarthritis: beyond the mechanical overload. Einstein (Sao Paulo). 2014;12:374-379.

67. Musumeci G, Aiello FC, Szychlinska MA, Di Rosa M, Castrogiovanni $\mathrm{P}$, Mobasheri A. Osteoarthritis in the XXIst century: risk factors and behaviours that influence disease onset and progression. Int J Mol Sci. 2015;16:6093-6112.

68. Vuolteenaho K, Koskinen A, Moilanen E. Leptin - a link between obesity and osteoarthritis. applications for prevention and treatment. Basic Clin Pharmacol Toxicol. 2014;114(1):103-8.

69. Issa RI, Griffin TM. Pathobiology of obesity and osteoarthritis: integrating biomechanics and inflammation. Pathobiol Aging Age Relat Dis. 2012;pii:17470.

70. Thorlund JB, Juhl CB, Roos EM, Lohmander LS. Arthroscopic surgery for degenerative knee: systematic review and meta-analysis of benefits and harms. Br J Sports Med. 2015;49:1229-1235.

71. Carr A. Arthroscopic surgery for degenerative knee: Overused, ineffective, and potentially harmful. Br J Sports Med. 2015;49:1223-1224.

72. Kise NJ, Risberg MA, Stensrud S, Ranstam J, Engebretsen L, Roos EM. Exercise therapy versus arthroscopic partial meniscectomy for degenerative meniscal tear in middle aged patients: randomised controlled trial with two year follow-up. BMJ. 2016;354:i3740.

73. Thompson SR. Diagnostic Knee Arthroscopy and Partial Meniscectomy. JBJS Essent Surg Tech. 2016;6:e7.

74. Lubowitz JH, Appleby D. Cost-effectiveness analysis of the most common orthopaedic surgery procedures: knee arthroscopy and knee anterior cruciate ligament reconstruction. Arthroscopy. 2011;27:1317-1322.

75. Salzler MJ, Lin A, Miller CD, Herold S, Irrgang JJ, Harner CD. Complications after arthroscopic knee surgery. Am J Sports Med. 2014;42(2):292-6.

76. Hagino T, Ochiai S, Miller CD, Herold S, Irrgang JJ, Harner CD. Complications after arthroscopic knee surgery. Arch Orthop Trauma Surg. 2014;134:1561-1564

77. Kuyucu E, Erdil M. Impact of Obesity on the Results of Arthroscopic Surgery of the Lower Extremity. Ann Orthop Rheumatol. 2016;4:1063.

78. Kluczynski MA, Marzo JM, Bisson LJ. Factors associated with meniscal tears and chondral lesions in patients undergoing anterior cruciate ligament reconstruction: a prospective study. Am J Sports Med. 2013;41:2759-2765.

79. Ciccotti MC, Kraeutler MJ, Austin LS, et al. The prevalence of articular cartilage changes in the knee joint in patients undergoing arthroscopy for meniscal pathology. Arthroscopy. 2012;28:1437-1444

80. Hwang BY, Kim SJ, Lee SW, et al. Risk factors for medial meniscus posterior root tear. Am J Sports Med. 2012;40:1606-1610

81. Ridley TJ, Cook S, Bollier M, et al. Effect of body mass index on patients with multiligamentous knee injuries. Arthroscopy. 2014;30:1447-1452.

82. Eskelinen AP, Visuri T, Larni HM, Ritsilä V. Primary cartilage lesions of the knee joint in young male adults. Overweight as a predisposing factor. An arthroscopic study. Scand J Surg. 2004;93:229-233.

83. Ford GM, Hegmann KT, White GL Jr, Holmes EB. Associations of body mass index with meniscal tears. Am J Prev Med. 2005;28:364-368.

84. Sturm R, Hattori A. Morbid obesity rates continue to rise rapidly in the United States. Int J Obes (Lond). 2013;37:889-891.

85. Berg EE. Knee joint arthroscopy in the morbidly obese. Arthroscopy. 1998;14:321-324. 
86. Martinez A, Hechtman KS. Arthroscopic technique for the knee in morbidly obese patients. Arthroscopy. 2002;18:E13.

87. Goode V, Rovnyak V, Hinton I, Phillips E, Merwin E. Are International Classification of Diseases Codes in Electronic Health Records Useful in Identifying Obesity as a Risk Factor When Evaluating Surgical Outcomes? Health Care Manag (Frederick). 2016:35(4):361-367.

88. Werner BC, Halim A, Miler MD, Gwathmey FW. Obesity Significantly Increases Postoperative Complications after Knee and Shoulder Arthroscopy. AAOS 2015 Annual Meeting; Las Vegas, Nevada. 2015. pp. 660.

89. Sing DC, Luan TF, Feeley BT, Zhang AL. Is Obesity a Risk Factor for Adverse Events After Knee Arthroscopy? Arthroscopy. 2016;32:1346-1353.

90. Erdil M, Bilsel K, Sungur M, et al. Does obesity negatively affect the functional results of arthroscopic partial meniscectomy? A retrospective cohort study. Arthroscopy. 2013;29:232-237.

91. Sommerfeldt MF, Magnussen RA, Randall KL, et al. The Relationship between Body Mass Index and Risk of Failure following Meniscus Repair. J Knee Surg. 2016. [Epub ahead of print]
92. Hage WK, Bollen SR, editors. Can ACL reconstruction be justified in the obese? 2012: Orthopaedic Proceedings.

93. Li RT, Lorenz S, Xu Y, Harner CD, Fu FH, Irrgang JJ. Predictors of radiographic knee osteoarthritis after anterior cruciate ligament reconstruction. Am J Sports Med. 2011;39:2595-2603.

94. Harrison MM, Morrell J, Hopman WM. Influence of obesity on outcome after knee arthroscopy. Arthroscopy. 2004;20:691-695.

95. Kowalchuk DA, Harner CD, Fu FH, Irrgang JJ. Prediction of patient-reported outcome after single-bundle anterior cruciate ligament reconstruction. Arthroscopy. 2009;25:457-463.

96. Spindler KP, Warren TA, Cllison CJ, Secic M, Fleisch SB. Clinical outcome at a minimum of five years after reconstruction of the anterior cruciate ligament. J Bone Joint Surg Am. 2005;87:1673-1679.

97. Christensen JC, Goldfine LR, Barker T, Collingridge DS. What Can the First 2 Months Tell Us About Outcomes After Anterior Cruciate Ligament Reconstruction? J Ath/ Train. 2015;50:508-515.

98. Nourissat G, Ciais G, Coudane H. Arthroscopy and obesity. Orthop Traumato/ Surg Res. 2015;101(8 Suppl):S351-S352. 